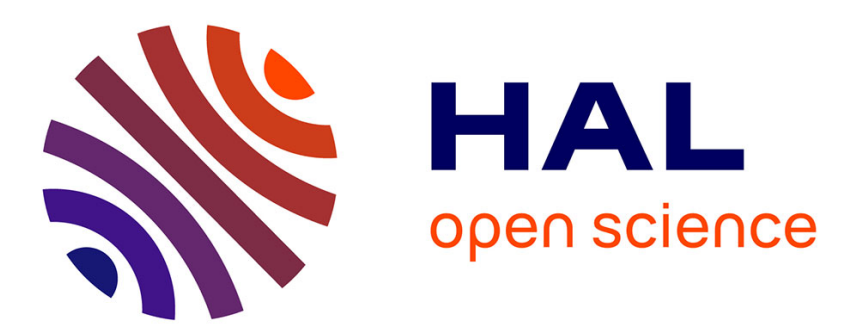

\title{
The Endocranial Cast of Indohyus (Artiodactyla, Raoellidae): The Origin of the Cetacean Brain
}

\author{
Maeva Orliac, J. Thewissen
}

\section{To cite this version:}

Maeva Orliac, J. Thewissen. The Endocranial Cast of Indohyus (Artiodactyla, Raoellidae): The Origin of the Cetacean Brain. Journal of Mammalian Evolution, 2021, 28 (3), pp.831-843. 10.1007/s10914021-09552-x . hal-03405524

\section{HAL Id: hal-03405524 \\ https://hal.science/hal-03405524}

Submitted on 27 Oct 2021

HAL is a multi-disciplinary open access archive for the deposit and dissemination of scientific research documents, whether they are published or not. The documents may come from teaching and research institutions in France or abroad, or from public or private research centers.
L'archive ouverte pluridisciplinaire HAL, est destinée au dépôt et à la diffusion de documents scientifiques de niveau recherche, publiés ou non, émanant des établissements d'enseignement et de recherche français ou étrangers, des laboratoires publics ou privés. 


\title{
Title: The endocranial cast of Indohyus (Artiodactyla, Raoellidae): the origin of the cetacean brain
}

\author{
by MAEVA J. ORLIAC ${ }^{1}$, J. G. M. THEWISSEN ${ }^{2}$ \\ ${ }^{1}$ Institut des Sciences de l'Évolution de Montpellier, Université de Montpellier, CNRS, IRD, EPHE, Place \\ Eugène Bataillon, 34095 Montpellier Cedex 5, France. \\ ${ }^{2}$ Department of Anatomy and Neurobiology, Northeast Ohio Medical University, 4209 State Route 44, \\ Rootstown, OH 44272, USA.
}

Corresponding author: Maeva J. Orliac; ORCID: 0000-0002-8922-8356; e-mail: maeva.orliac@umontpellier.fr

\begin{abstract}
We present the first description of the endocranial cast of the small raoellid artiodactyl Indohyus indirae. Raoellidae are sister group to Cetacea and the new morphological observations allow for outlining some of the early steps of the evolutionary history of the cetacean brain. The combination of primitive artiodactyl features and typical cetacean characters is unique about the Indohyus endocast. The fact that it presents the symplesiomorphic brain pattern observed in earliest Artiodactyla indicates that the cetacean brain derives from a very simple, plesiomorphic brain, with simple neocortical folding pattern, widely exposed midbrain, and concurrent small neocortex expansion. On the other hand, the Indohyus endocast shows characters that also occur in early cetaceans. These include modifications of the olfactory tract with narrow, elongated olfactory bulbs and peduncles, accompanied by a posterior location of the braincase in the cranium. The derived endocranial cast features of Indohyus mainly reflect changes in cranial architecture and these are most probably associated with modifications of the masticatory apparatus and a shift in diet. Indohyus meninges were very thin like in most terrestrial artiodactyls and it had no extensive rostral or lateral retia mirabilia. It however shows a branching pattern of ramification of intraosseous blood sinuses above the cerebellum that might represent the initial development of the caudal venous rete mirabile that would have colonized the endocranial cavity later on, in early archaeocetes.
\end{abstract}

Keywords: endocast, Eocene, Cetacea, CT scan, brain

\section{Declarations}

Funding: This work was, in part, financially supported by the ANR program DEADENDER (ANR-18-CE02- 0003-01) headed by M. J. Orliac.

Competing interests: The authors declare having no competing interests.

\section{Data archiving and supporting information}

Data for this study are available in the MorPhoMuseuM online platform Repository: http://dx.doi.org/ doi: 10.18563/journal.m3.XX; models ids: M3\#710_RR207; M3\#711_RR601.

Additional Supporting Information can be found in the online version of this article: 
Appendix S1. Additional illustrations of the endocranial structures of Indohyus indirae.

\section{Acknowledgments}

We are grateful to G. Thiery and S. Ducroqc (PALEVOPRIM) for granting access to the $\mu \mathrm{CT}$ scan data of the Microbunodon minimum cranium from La Milloque. We thank J. Maugoust 5ISEM) for fruitful discussions on brain structures. J.G.M. Thewissen would like to thank the Hennecke Family Foundation for funding. We thanks M. Mourlam (ISEM) for his help during scanning, and R. Lebrun for the access of scanning facilities (MRI platform member of the national infrastructure France-BioImaging supported by the French National Research Agency [ANR-10-INBS-04, «Investments for the future»], the LabEx CEMEB [ANR-10LABX-0004] and NUMEV [ANR-10-LABX-0020]). We are grateful to the two anonymous reviewers for their helpful comments and to J.R. Wible for his thorough proofreading and useful remarks. This work was supported by the ANR DEADENDER [ANR-18-CE02-000301].

\section{INTRODUCTION}

Cetaceans occupy a peculiar place within the evolutionary history of Artiodactyla. Their adaptation to obligate aquatic life involved drastic morphological transformations from the terrestrial bauplan of their closest relatives and exemplifies one of the most spectacular cases of eco-morphological transformation within Mammalia. Among other distinctive features, crown cetaceans (Neoceti) exhibit a peculiar brain morphology. Macroscopically, the brain of extant whales is characterized by the reduction or loss of the olfactory apparatus (microsmatic mammals; e.g., Edinger 1955; Pihlström 2008; Godfrey et al. 2013; Berta et al. 2014; Kishida et al. 2015), a complex neocortex with huge cerebral hemispheres (e.g., Marino 2002; Marino et al. 2004, 2007; Hof et al. 2005). In addition, there is an extraordinary development of the acoustic system where the caudal colliculi of the midbrain (which receive input from the ears) are much larger than the rostral colliculi (which mostly receive visual input; Ogawa 1948; Edinger 1955). Part of the cetacean brain, especially in mysticetes, is surrounded by a dense network of arteries and veins called the rete mirabile, "wonderful net" (Slijper 1936; Ridgway et al. 2016). Finally, the cetacean brain is second only to humans among mammals in brain size, as scaled for body allometry (Worthy and Hickie 1986; Ridgway and Tarpley 1996; Marino 1998).

Natural endocranial casts of basilosaurids, fully aquatic archaeocetes sister taxon to Neoceti (Martínes-Cáceres et al. 2017), reveal some features of the cetacean brain around 4034 million years ago (Smith 1903; Dart 1923; Edinger 1955; Marino et al. 2000; Uhen 2004). However, morphology of the brain of these large animals is difficult to observe because in the endocast it is covered by a venous plexus consisting of dural blood vessels (part of the retia mirabilia) that most likely developed as an adaptation to aquatic lifestyle (Geisler and Luo 1998; Uhen 2004). The earliest evolutionary history of the cetacean brain is documented to some degree by early middle Eocene archaeocetes, pakicetids (Nummela et al. 2006; Kishida et al. 2015), protocetids (Bajpai et al. 1996), and remingtonocetids (Bajpai et al. 2011; Kishida et al. 2015), but our understanding remains incomplete. The morphology of the archaeocete brain was strikingly different from that of modern cetaceans, but also from that of 
their contemporaneous terrestrial artiodactyl relatives. Main evolutionary modifications include the olfactory tract (Edinger 1955; Bajpai et al. 2011; Berta et al. 2014; Kishida et al. 2015), and presence of wide venous sinuses lateral to the brain (associated with the rete mirabile; Indocetus ramani, Bajpai et al. 1996; Remingtonocetus, Bajpai et al. 2011).

In this work, we describe the external features of the brain and associated sinuses of a Raoellidae, small-sized semiaquatic Artiodactyla that are the closest relatives to the Cetacea clade (Thewissen et al. 2007; Cooper et al. 2012; Orliac and Ducrocq 2012; Gatesy et al. 2013). Raoellid remains are documented from middle Eocene deposits of south Asia, coeval with early cetaceans and found in the same fossil yielding localities (Thewissen et al. 2001, 2007, 2009). Our work is based on the virtual reconstruction of the endocranial cast of two crania referred to Indohyus indirae and collected at a middle Eocene bone bed in India. Knowledge of the raoellid brain morphology helps to bridge the gap between cetacean and their non-cetacean fully terrestrial relatives and allows for discussing the earliest phase of differentiation of the cetacean brain.

\section{MATERIAL AND METHODS}

Our study is based on the two crania RR 601 and RR 207 referred to Indohyus indirae (Ranga Rao1971, 1972; Sahni and Khare 1972), collected at a middle Eocene bone bed at the locality Sindkhatudi in the Kalakot region of Kashmir (Thewissen et al. 2001, 2007). Both specimens represent fully adult individuals, with fully erupted M3 and moderate state of wear of the dentition. The ventral view of the specimen RR 207 was illustrated by Thewissen et al. (2007:fig.1b). The two specimens are curated at the Northeast Ohio Medical University. The 3D data acquisition of the two specimens was performed at the $\mu$-CT scanner facility of the Montpellier Rio Imaging platform (MRI) at the University of Montpellier, using an EasyTom $150 \mu$-CT scanner. The voxel size is of $91.2 \mu \mathrm{m}$. Segmentation and measurements were performed using Avizo ${ }^{\circledR} 9.3$ (Thermo Fisher Scientific-FEI). Segmentation was performed manually slice by slice using the pencil segmentation tool. Endocast, sinuses, petrosal bones, bullae, and external auditory meatus were segmented separately on different label fields. Labelled 3D models of the various endocranial structures described in this work are available for visualisation and download at MorphoMuseuM (Lebrun and Orliac 2014; models ids: M3\#710_RR207; M3\#711_RR601).

\section{RESULTS}

\section{General shape and preservation of the specimens}

The specimens RR 207 and RR 601 have undergone significant dorso-ventral compression and slight lateral deformation (Fig. 1), making it impossible to reconstruct the original breadth and height of their braincase with confidence. In addition, several morphological features of the endocranial cast cannot be observed or measured. Measurements that appear unaffected by deformation are provided in Table 1. The general arrangement of the different parts of the brain cannot be determined with accuracy. The dorsal aspect of the endocasts is best preserved in RR 207, while the ventral surface is best seen in 
RR 601 (Fig. 2). Despite the dorsoventral compression, the vermis of the cerebellum constitutes the highest point of the brain on RR 601; it might also have been the case for RR 207, but the posteroventral shift of the nuchal part of the cranium has deformed the cerebellum. The length of the olfactory peduncles and bulbs is approximately one-third of the total length of both endocranial casts (Figs. 2B, 3B, Table 1). Strong impressions of the neocortical sulci on the internal aspect of the frontal and parietal bones indicate that the meninges had a negligible thickness.

\section{Rhinencephalon}

The brain ends anteriorly by the preserved portions of the cribriform plate (Figs. 2D, 3S1). The ethmoidal chambers, housing the olfactory bulbs, reach the level of the anterior margin of the orbit (Fig. 1A-B). They are narrow and anteroposteriorly elongated, and left and right chambers are fused for most of their length. The whole olfactory tract is elongated, and almost represents one-third of the total length of the endocranial cast (33.5 (RR 207)-31.8 (RR 601) \% of the length of the endocranial cast in dorsal view). The olfactory lobes are visible as elongated swellings, slightly larger than the long olfactory peduncles. The cast of the cribriform plate, showing the pattern of olfactory nerves is partly visible on RR 207 and reveals the presence of rounded equidistant pits similar to those observed in Pakicetus (Kishida et al. 2015: fig. 3). In dorsal view the olfactory tract represents 33.5 (RR 207)-31.8 (RR 601) \% of the length of the endocranial cast. The width of the olfactory peduncles makes up the entire breadth of the postorbital constriction of the skull (Fig. 3AS2). The area of the olfactory tubercles and piriform lobes is poorly preserved. The location of the posterior rhinal fissure and a depression on the ventral surface that is interpreted here as the ventral delineation of the piriform lobes indicate that these lobes were relatively small compared to the neocortex size. The orbitotemporal canal runs across the piriform lobe, below the level of the rhinal fissure (Figs. 2A,E, S1).

\section{Neopallium}

The neopallium is located in the posterior part of the cranium and the entire cerebral hemispheres are posterior to the orbit (Fig. 1). The dorsal part of the neocortex is best preserved in RR 207, but both specimens present the plesiomorphic artiodactyl pattern with the lateral and suprasylvia sulci, forming a narrow, almond shape, gyrus 3 (Fig. 2A-B). These sulci meet anteriorly in a deep, elongated depression here interpreted as the coronal sulcus (Figs. 2A-B, 3AS4). The anterior margin of the neocortex is faint, almost continuous with the olfactory peduncles. The rhinal fissure is best seen in the anterior portion of the endocranial cast; it is shallow and indicates the anterior margin of the neocortex (Figs. 2-3AS3). The latter covers a wide portion of the cerebral hemispheres. The exact shape of the neopallium cannot be determined due to deformation, but the general shape was pear- or teardrop-shaped, and it is distinctly narrower anteriorly. The dorsal sagittal sinus is salient and separates the two cerebral hemispheres. There is no trace of transverse sinus on the posterior margin of the cerebrum.

\section{Midbrain}


There is a significant distance between neopallium and cerebellum, and the tectum of the midbrain is broadly exposed medially in a deep depression, anterior to the vermis (Figs. 23 ). Left and right caudal colliculi are visible on the dorsal aspect of the endocast as distinct swellings in RR 207, somewhat larger on the right side (Figs. 2-3S5, black arrows; Fig. S1). The tentorium cerebelli did not leave an impression.

\section{Cerebellum}

The cerebellum (RR 207) is large and the vermis is distinct. The cerebellar hemispheres (lateral lobes) are small and partly covered dorsally by the superior petrosal sinus; the extent of their anterior and lateral extensions are difficult to determine (Fig. 2A-B). In dorsal view, the vermis of the cerebellum is wide and elevated, pear-shaped, and narrows anteriorly. Its dorsal extension reaches the same level as the dorsal surface of the telencephalon (Fig. 2E-F). The small cerebellar hemispheres are separated from the vermis by broad and shallow paramedian fissures. In dorsal view, their anterior extension seems to be anterior to that of the vermis, while the latter protrudes posteriorly. On the lateral surfaces, the paraflocculi are barely visible: the subarcuate fossa of the petrosal is very shallow, and its cast consists in a discrete swelling on the course of the superior petrosal sinus cast (Fig. 2E-F).

\section{Nerves and sinuses}

The ventral side of the endocast is deformed in the region of presphenoid, pterygoid, and basisphenoid bones in both specimens. The cribriform plate is perforated by several foramina for the olfactory nerve fascicles (cranial nerve I, CN I) (Figs. 2D, 3S1). The optic chiasma of the optic nerves (CN II) is visible on both specimens, located posterior to the basis of the olfactory peduncles; it lies posterior to the postorbital process of the cranium (Fig. 1C). The sphenorbital fissure transmits vessels and cranial nerves III to VI, except for CN V.3. As in other artiodactyls, it does transmit CN V.2. It opens medially on the endocast, almost on the same anteroposterior line as the posterior margin of the optic chiasm. There are two separate grooves leading to this fissure, the medial one could correspond to the pathway of the oculomotor nerve (CN III), while the lateralmost might correspond to a separate pathway for CN V.1 and V.2. The foramen ovale lies posterolateral to the sphenorbital fissure and contains CN V.3. Details of the pituitary fossa cannot be distinguished due to deformation, but it is visible on both specimens as a wide triangular swelling lying between the petrosal bones. The casts of the facial (CN VII) and vestibulocochlear (CN VIII) nerves are visible, especially in RR 207 (Fig. 2F). The cast of the piriform fenestra connects the jugular foramen via the slit of the basicapsular fissure. Posterior to it, the cast of the hypoglossal foramen, where CN XII leaves the skull, is clear on the side of the medulla oblongata.

In both specimens, the cerebral hemispheres are separated by a salient dorsal sagittal sinus. It is elongated in the sagittal plane by a continuous and pronounced ridge that extends posteriorly to the anterior margin of the vermis. The transverse sinus appears as a faint transverse bridge (Figs. 2A, 4A, S1). The wide cast of the superior petrosal sinus partly hides the cerebellar hemispheres in dorsal view; in lateral view, the cast of the sigmoid sinus is also 
clearly visible (Figs. 2E-F, 4C). Micro-CT scan investigation also allows for reconstructing intra-osseous sinuses, reconstructed for RR 207 and illustrated in Fig. 4. In addition to the superior petrosal sinus that partly hides the cerebellar hemispheres, a large sinus is present laterodorsally and anteriorly to the petrosal bone (also observed in the specimen RR 601, Fig. S2). This sinus corresponds to the temporal sinus cavity (Hoffmann et al. 2014; pathway for the capsuloparietal emissary vein, Wible 2011). Part of it opens dorsally onto a wide temporal foramen (temporal foramina = foramina for rami temporales; see Giannini et al. 2006) located close to the nuchal crest (Fig. 4). Another small canal opens dorsally on the lateral side of the squamosal, dorsal to the glenoid surface, and most probably corresponds to a tributary to the capsuloparietal emissary vein (Figs. 3S5-7, 4). Posteriorly, the temporal sinus cavity connects to the sigmoid sinus pathway (corresponding to the posterior distributary branch of the transverse sinus; Wible, 1993). Laterally, it opens on the posteroventral surface of the cranium, posterior to the glenoid surface into the postglenoid foramen. This canal probably mainly corresponds to the pathway of the capsuloparietal emissary vein, which exits the cranium via the postglenoid foramen (ventral aperture of the capsuloparietal emissary vein, Wible 1990; Geisler and Luo 1998). A small opening occurs near the postglenoid foramen, it is located between the anterior wall of the external auditory meatus and the medial most portion of the postglenoid process (Figs. 4A, S3). Yet, another small canal lies between the temporal sinus and the lateral wall of the auditory bulla. It opens ventrally into a foramen located between the squamosal and the bulla in a location that corresponds to the foramen recognized as the postglenoid foramen in early cetaceans (Geisler and Luo 1998; Geisler et al. 2007) and labelled "vascular foramen" by Geisler and Luo (1998:fig.8; see discussion for homology hypotheses). Left and right temporal sinuses are connected by a dorsal confluence of sinuses (dashed circle on Fig. 4A; similar to that described for the camel by Jerby et al. 2018:fig.3), at the level of the midbrain. A dorsal canal runs into the parietal bone and seems to prolong the sagittal sinus and to drain in the confluence of sinuses.

The cast of the endocranial cavity at the vermis level shows two longitudinal ridges corresponding to blood vessel pathways (Fig. S1). They connect a network of intraosseous sinuses that lie between the parietal and occipital bones, and within the occipital (posterior occipital sinus Figs. 3S8, 4, S2; ?occipital sinus of Butler 1967). It opens into the cranial cavity at the level of the sigmoid sinus anteriorly (Figs. 3S8, 4C-D), and outside the cranium, on the occipital aspect of the skull, at the level of the mastoid foramen (Fig. 4B). This posterior occipital sinus might have housed diploic veins and arteries. The mastoid foramen might have given pathway to the occipital emissary vein (Wible 2008, 2011), and/or to the vena diploetica magna (Geisler and Luo, 1998). Cast of the pathway for the condyloid vein can also easily be reconstructed, emerging laterally to the main sinus imprint exiting the cranium by the foramen magnum. Based on the reconstruction of both the intraosseous sinuses and the sinuses imprints on the endocranial cavity, we provide a schematic reconstruction of the venous pattern in the posterior portion of the cranium in lateral view (Fig. 4D) showing the relationship between major venous structures.

\section{DISCUSSION}

Primitive features of the brain of Indohyus indirae 
The endocranial cast of Indohyus indirae exhibits general primitive features shared with other early artiodactyls. Overall, the cast of the braincase, with impressions of the neocortical sulci pattern and blood vessels, indicates that meninges were very thin, as in other Eocene artiodactyls described in the literature (e.g., Dechaseaux 1969; Macrini 2009; Orliac and Gilissen 2012). The neocortical pattern, with two main cortical sulci delimiting gyrus 3, and the wide exposure of the midbrain are consistent with the morphology of the earliest artiodactyls from the early and early middle Eocene such as Diacodexis, Homacodon, and Helohyus (Orliac and Gilissen 2012). Compression of the cerebrum makes it difficult to accurately determine its shape. However, the location of the rhinal fissure indicates that the neocortex was relatively small, as it is plesiomorphically in artiodactyls (Orliac and Gilissen 2012). Possibly related to the weak posterior expansion of the neocortex, the midbrain exposure in Indohyus is greater than in middle and late Eocene endemic European artiodactyls like Dichobune, Cebochoerus, Tapirulus (Dechaseaux 1961, 1969; Orliac and Gilissen 2012), and Eocene North American taxa like Agriochoerus, and the merycoidodontids (e.g., Whitmore 1953; Dechaseaux 1961; Macrini 2009; Orliac and Gilissen 2012). The caudal colliculi (colliculi caudalis) of the mesencephalon are exposed (Figs. 2, S1), which is, to our knowledge, the only occurrence of exposed colliculi described in artiodactyls. The caudal colliculi are major components of the integration of the auditory information (Malmierca et al. 2002). Modern cetaceans have highly enhanced auditory skills and concurrently show greatly enlarged caudal colliculi compared to terrestrial mammals (Marino et al. 2003). The fact that Indohyus shows dorsally protruding caudal colliculi, while other early artiodactyls with widely exposed midbrain tectum do not, could indicate that caudal colliculi are bigger in this taxon, suggesting underlying specialization of the auditory integration. It is however impossible to say if, in Indohyus, the dorsal protrusion of the caudal colliculi is related to a plesiomorphic wide exposure of the midbrain or to a derived size increase of these structures. Another noticeable feature that differs between the brain of modern Cetacea and the endocast of Indohyus lies in the relatively large size of its vermis compared to the cerebellar hemispheres (e.g., similar relative size as in Diacodexis or Dichobune, Fig. 5). Modern Cetacea are characterized by a very small and narrow vermis compared to the two voluminous, highly convoluted, cerebellar hemispheres (e.g., Ries and Langworthy 1937; Pilleri 1966a,b; Hanson et al. 2013; Bisconti et al. 2021). Regarding archaeocetes, little of the cerebellum is visible on cranial endocasts of basilosaurids as most of its surface is covered with a large rete mirabile (e.g., Breathnach 1955; Pilleri 1991; Geisler and Luo 1998; Uhen 2004), making it impossible to observe the relative size of the vermis accurately. The endocasts of the protocetid Indocetus (Bajpai et al. 1996) and the remingtonocetid Remingtonocetus (Bajpai et al. 2011), despite noticeable rete mirabile expansion, show a relatively wide vermis relative to the plausible representation of the cerebellar hemispheres, indicating that major shift in the proportions of the different elements of the cerebellum might have occurred in Pelagiceti.

Regarding the general pattern of basicranial foramina and openings (postglenoid foramen excepted, see bellow), Indohyus is similar to early artiodactyls like Diacodexis or Homacodon (Coombs and Coombs 1982). It does not exhibit the 'cranial hiatus' observed in some cetaceans. This feature, associated with the ventrolateral displacement of the ear bones, 
corresponds to the space through which pass cranial nerves, blood vessels, and is (in life) largely filled by the petrotympanic and peribullar sinuses (Fraser and Purves 1960; Mead and Fordyce 2009). Nummela et al. (2007: fig.8) show a gradual detachment of the petrotympanic from the skull in Eocene clades of cetaceans, and this would correspond to developing a more distinct cranial hiatus. These wide sinuses surrounding the ear region are not present in Indohyus in which the mastoid part of the petrosal is tightly fused to the cranial wall (Fig. 3S5-6).

The fact that raoellids, sister taxon to Cetacea, share the symplesiomorphic brain pattern observed in the earliest Artiodactyla (early-middle Eocene taxa such as Diacodexis, Homacodon, Helohyus, Cebochoerus; Orliac and Gilissen 2012) indicates that the cetacean brain derives from a very simple, plesiomorphic brain, with a simple and little expanded neocortex. This finding provides context for the peculiar neocortical organization of the modern cetacean brain and its simple cortical organization ("initial brain" hypothesis, Glezer et al. 1988, 1993). Indeed, despite the extreme size and the highly convoluted neocortex of modern cetaceans, histological studies revealed a rather simple underlying neocortical organization. This includes neocortex lamination with extremely wide layer I and a very small to incipient to totally absent layer IV depending on the areas (Morgane et al. 1988; Raghanti et al. 2019) when compared to later artiodactyl clades (Morgane et al. 1985, 1988; Glezer et al. 1988, 1993). The fact that the cetacean brain derives from a very simple plesiomorphic artiodactyl brain type would be congruent with the retention of a plesiomorphic neocortex organization in this otherwise highly derived artiodactyl clade, as proposed by Glezer et al. (1988, 1993).

\section{Early steps of the evolutionary history of the brain of Cetacea}

Olfactory tract, smell, and postorbital region elongation. Unlike other artiodactyls, Indohyus has narrow olfactory bulbs and elongated olfactory tract, bulbs, and peduncles, accompanied by a narrow, slightly elongated intertemporal region immediately posterior to the orbit. Narrowing of the intertemporal region is a common feature in early cetaceans such as pakicetids (Nummela et al. 2006), ambulocetids (e.g., Ambulocetus; Thewissen et al. 1996), and remingtonocetids (Thewissen and Bajpai 2009; Bajpai et al. 2011). Nummela et al. (2006) and Thewissen et al. (2007) proposed this as an important diagnostic character for the order Cetacea. An elongation of the olfactory tract has also been described in these groups (Pakicetidae, Kishida et al. 2015; Remingtonocetidae, Bajpai et al. 2011). The narrowing and lengthening of the olfactory bulbs of Indohyus and early cetaceans (e.g., Remingtonocetus, Bajpai et al. 2011:fig.6; Kishida et al. 2015:fig.3c; Fig. 5) might be directly related to modifications of the intertemporal region. Given the phylogenetic relationships supporting Raoellidae as sister taxon to Cetacea (Thewissen et al. 2007) and according to observations available from various artiodactyl endocasts (some examples in Fig.5; e.g., Dechaseaux 1969; Orliac and Gilissen, 2012), this character would be inherited from the common hypothetical ancestor to Raoellidae and Cetacea (and thus a synapomorphy of the clade; Fig. 5). In Indohyus, the location of the anterior extremity of the brain, as marked by the location of the cribriform plate, is similar to that of other artiodactyls and lies close to the level of the anterior margin of the orbit (Fig. 5). However, the entire cerebral hemispheres lie posterior to 
the postorbital bar (Fig. 5E), as in Remingtonocetus (Fig. 5F), and Dorudon (Edinger 1955:fig.7). To our knowledge, this posterior location of the braincase is not observed in noncetacean artiodactyls (Fig. 5A-D) and accompanies the elongation of the olfactory tract and of the intertemporal region.

In archaeocetes, the elongation of the postorbital portion of the cranium has been interpreted to be related to food intake or food processing: i) breathing and compartmentalization of the oral cavity at the level of the choanae (narrow nasopharyngeal duct), ii) lengthening of the out-lever of the masticatory muscles, increasing the closing speed of the jaws (Thewissen et al. 2007). In Indohyus, the elongation of the postorbital portion of the cranium is slight, and there is no posterior extension of the nasopharyngeal duct (choanae open at the level of the third upper molar, Thewissen et al. 2007:fig.1b). Indohyus, however, has a high sagittal crest and a wide temporal fossa for masticatory muscles (Figs. 1, 3, S2). The very wide canal for blood supply of the temporal area of the cranium (ramus temporalis of veins and arteries) suggests the presence of strong masticatory muscles, which exert physical constraints on the braincase and shape the postorbital portion of the cranium. This suggests that the modification of the postorbital morphology and the concurrent elongation of the olfactory tract would primarily originate from modifications of the masticatory apparatus, related to specialized diet. In addition, raoellids and early cetaceans further share derived dental characters that can be correlated to a functional adaptation to shearing, with simple and trenchant premolars (Theodor et al. 2007; Thewissen et al. 2007) and specialization of their upper and lower premolars to form a complementary shearing device (Orliac and Ducrocq 2012), suggesting some similarities in food processing.

Regarding the olfactory abilities of Indohyus, if it is impossible to determine the volume of the olfactory bulbs of this taxon due to the flattening of the two specimens, the preserved portions of the cribriform plates indicate that these structures, with a wide surface and perforated by several foramina (Fig. 2D), were fully functional. Diminution in size of the olfactory bulbs is observed in cetacean history and parallels their adaptation to a fully aquatic life (Kishida et al. 2015). Loss or reduction of the sense of smell in cetacean has been extensively discussed in the literature (e.g., Edinger 1955; Godfrey et al. 2013; Berta et al. 2014; Kishida et al. 2015) and profound changes in the chemosensory capabilities most probably occurred early in cetacean evolutionary history, at the land to water transition (Kishida et al. 2015). Based on its olfactory bulbs size and afferent olfactory fiber density, Indohyus most probably had a fully functional sense of smell, indicating that the alteration of the olfactory functions occurred later in cetacean history.

Neocortex size and gyrification. Increased neocortical size and complexity is one of the hallmarks of the modern cetacean brain (Marino et al. 2000, 2004, 2007). The presence of extensive retia mirabilia makes it impossible to access the neocortical pattern of fossil cetaceans, and the neocortical fissuration pattern of early whales remains largely unknown, as evidenced by basilosaurids in which the pattern could not be described (Pilleri 1991). In protocetids and remingtonocetids, the extension of the retia is limited and the presence of three faint oblique sulci has been mentioned on a natural endocranial cast of the protocetid Indocetus by Bajpai et al. (1996). Unfortunately, they cannot be identified based on the illustration provided (Bajpai et al. 1996:fig.1). In the 3D reconstruction of the endocast of 
Remingtonocetus harudiensis, a faint cerebral sulcus lateral to the cerebral midline is present, but the overall low detail of the 3D model due to the size of the specimen makes it impossible to study the cerebral sulci in more detail (Bajpai et al. 2011:fig.7). The presence of a very simple neocortical fissuration pattern, limited to two major neocortical sulci (suprasylvia and lateral sulcus) plus a small coronal sulcus, in Indohyus indirae indicates that the primitive pattern for Cetacea derives from the same general primitive neocortical pattern retrieved in other artiodactyls. The "artiodactyl cortical blueprint" is also valid for cetaceans (Orliac and Gilissen 2012). However, the limited information regarding the neocortical fissuration pattern in early cetaceans is not sufficient to determine the evolution of neocortical folding at the first nodes of the cetacean tree.

The extension of the neocortex of Indohyus indirae is very limited, in particular on the posterior aspect of the brain, and as a result the midbrain is widely exposed (Fig. 2). The natural endocast of Indocetus (Bajpai et al. 1996:fig.1C) and the 3D reconstruction of the endocranial cast of Remingtonocetus (Bajpai et al. 2011:fig.7) show that they had a proportionally bigger, more posteriorly expended neocortex, that covered the midbrain and contacted the cerebellum. If early archaeocetes were probably not capable of echolocation (Mourlam and Orliac 2017), their auditory system was already modified for underwater hearing (e.g., impedance match; underwater directional hearing; Mourlam and Orliac 2017, 2019), and increase of neocortex size in early archaeocetes has been hypothesized to relate to an expansion of the auditory cortex, which occupies a wide area of the cetacean neocortex (e.g., Hof and Van der Gucht 2007; Knopf et al. 2015).

Retia mirabilia and sinuses. Modern terrestrial artiodactyls have a rostral rete mirabile epidurale lying on the basisphenoid roof, slightly posterior to the fossa hypophysalis (O'Brien 2015:fig.1). The intracranial retia observed in modern cetaceans greatly differ from the rete mirabile of other artiodactyl groups by their size and position: (i) the rostral arterial rete is more extensive (e.g., McFarland et al. 1979; Vogi and Fisher 1981a), (ii) there is a caudal endocranial arterial and venous rete mirabile (in mysticetes only; Breathnach 1955; Pilleri 1991; Melnikov 1997), and (iii) high vascularization of the pneumatic sinuses around the petrosal and ectotympanic bulla, and presence of various retia in the basicranium (Fraser and Purves 1960). Regarding early whales, basilosaurids already present a hypertrophied caudal rete and extensive sinuses around and lateral to the ear region (Breathnach 1955; Pilleri 1991; Geisler and Luo 1998). In protocetids, the rugose surface of the endocranial space at the cerebellum location in Indocetus has been interpreted as indicative of a venous rete, dorsal to the cerebellum, and a caudal rete mirabile would be present medial and dorsomedial to the petrosal (Bajpai et al. 1996:fig.lA). In the remingtonocetids Dalanistes ahmedi (Gingerich et al. 1995) and Remingtonocetus harudiensis (Bajpail et al. 2011), a rete also probably filled the region dorsomedial to the petrosals. In these taxa, there is little evidence that neither the caudal nor the rostral rete were extensive. In Indohyus the cast of the braincase shows impressions of neocortical sulci and blood vessels indicating that meninges were very thin like in most artiodactyls and that there were no extensive rostral or lateral retia mirabilia. There is no significantly enlarged space around the petrosal and bulla either. However, the intraosseous space dorsal to the cerebellum might have housed a network of diploic veins and arteries (Figs. 3S6-7, 4). This network is larger and branches more than in Eocene artiodactyls 
of our sample (Figs. S4-5) and might represent the first steps of an incipient caudal venous rete mirabile. The latter would have colonized the endocranial cavity later on in protocetids.

Another character of potential interest is the location of the postglenoid foramen, which is the ventral aperture of the capsuloparietal emissary vein (Wible 1990; Geisler and Luo 1998). The latter is absent in modern cetaceans (Slijper 1936; Geisler and Luo 1998), but it is present in early archaeocetes, as evidenced by the postglenoid foramen. Contrary to most Artiodactyla, where the postglenoid foramen is located posterior to the postglenoid process, in the squamosal, the postglenoid foramen of early cetaceans (protocetids, and basilosaurids; Geisler and Luo 1998; Geisler et al. 2007) is situated more medially, on the petrosal/squamosal suture. This character state has been proposed as a synapomorphy of the (Cetacea, Hippopotamoidea) clade (Geisler et al. 2007). We show here that Indohyus presents both a wide (double) postglenoid foramen fully enclosed within the squamosal (Figs. 3S7, 4), and a secondary foramen opening medially between the squamosal and the auditory bulla (Fig. S3). This pattern is a mosaic of the plesiomorphic artiodactyl pattern and the derived condition described in protocetid and basilosaurid archaeocetes by Geisler and Luo (1998). It is worth noting that in the pakicetids Pakicetus and Nalacetus (Nummela et al. 2006:fig.5), as well as in Ichthyolestes (HGSP 98134), the position of the postglenoid foramen, posterior to the postglenoid process, does not differ much from what we describe here in Indohyus, questioning the location of the postglenoid foramen at the petrosal/squamosal suture as a Cetacea character state. Hippopotamoidea also have a postglenoid foramen and, in addition, a medial, secondary foramen (Geisler et al. 2007:fig. 3.3; Orliac et al. 2013, 2014:fig.1). Additional study of the capsuloparietal emissary vein pathway in early artiodactyls and its character coding is necessary to assess the systematic importance of the postglenoid in artiodactyls.

\section{CONCLUSIONS}

This first description of the endocranial cast of a Raoellidae, the sister group to Cetacea, allows for determination of the early evolutionary history of the cetacean brain. The combination of primitive artiodactyl features and typical cetacean characters in Indohyus is striking. The symplesiomorphic brain features observed in earliest Artiodactyla, including Indohyus, indicate that the cetacean brain derives from a very simple, plesiomorphic brain, with simple neocortical folding pattern, widely exposed midbrain and concurrent small neocortex expansion. On the other hand, the Indohyus endocast shows characters that occur in early cetaceans and are probably synapomorphies of the (Raoellidae, Cetacea) clade. These include modifications of the olfactory tract with narrow elongated olfactory bulbs and peduncles, accompanied by a posterior location of the braincase in the cranium, where the cerebrum is entirely posterior to the postorbital bar. Indohyus also shows a branching pattern of ramification of intraosseous blood sinuses lying above the cerebellum that might represent the initial development of the caudal venous rete mirabile that would have colonized the endocranial cavity later on, in early archaeocetes.

The derived endocranial cast features of Indohyus mainly reflect changes in cranial architecture and these are most probably associated with modifications of the masticatory apparatus (i.e., elongation and narrowing of the postorbital portion of the cranium) and a shift 
in diet. Raoellids have been interpreted as aquatic dwellers (Thewissen et al. 2007, 2009; Thewissen 2014; Cooper et al. 2016). Yet, the size and morphology of the cribriform plate indicate that this animal had a fully functional sense of smell as its fully terrestrial relatives. Regarding hearing, Raoellidae share with Cetacea a unique cranial feature that is the thickening of the medial wall of the auditory bulla known as the involucrum (Thewissen et al. 2007). This feature has been associated with underwater hearing (Luo and Gingerich 1998; Nummela et al. 2004; Geisler et al. 2005) and also might be related with aquatic habits in raoellids. The presence of exposed caudal colliculi at the midbrain further questions a specialisation of the auditory system in this groups.

This study extends the list of the derived features shared between Raoellidae and Cetacea (e.g., presence of an involucrum, Thewissen et al. 2007; premolar morphology, Thewissen et al. 2007; Orliac and Ducrocq 2012; osteoclerotic limb bones, Thewissen et al. 2009; Cooper et al. 2016) and would support the inclusion of Raoellidae into an extended definition of the Cetacea clade.

\section{REFERENCES}

Bajpai S, Thewissen JGM, Conley RW (2011) Cranial anatomy of middle Eocene Remingtonocetus (Cetacea, Mammalia) from Kutch, India. J Paleontol 85(4):703-718

Bajpai S, Thewissen JGM, Sahni A (1996) Indocetus (Cetacea, Mammalia) endocasts from Kachchh (India). J Vertebr Paleontol 6:582-584

Berta A, Ekdale EG, Cranford TW (2014) Review of the cetacean nose: form, function, and evolution. Anat Rec 297(11):2205-2215

Bisconti M, Damarco P, Tartarelli G, Pavia M, Carnevale G (2021). A natural endocast of an early Miocene odontocete and its implications in cetacean brain evolution. J Comp Neurol 529(6):1198-1227

Breathnach AS (1955) Observations on endocranial casts of recent and fossil cetaceans. J Anat 89:532-546

Butler H (1967) The development of mammalian dural venous sinuses with especial reference to the post-glenoid vein. J Anat 102:33-56

Coombs MC, Coombs WP (1982) Anatomy of the ear region of four Eocene artiodactyls: Gobiohyus,? Helohyus, Diacodexis and Homacodon. J Vertebr Paleontol 2(2):219-236

Cooper LN, Clementz MT, Usip S, Bajpai S, Hussain ST, Hieronymus TL (2016) Aquatic habits of cetacean ancestors: integrating bone microanatomy and stable isotopes. Integr Comp Biol 56(6):1370-1384

Cooper LN, Thewissen JGM, Bajpai S, Tiwari BN (2012) Postcranial morphology and locomotion of the Eocene raoellid Indohyus (Artiodactyla: Mammalia). Hist Biol 24(3):279-310

Dart RMA, Andrews CW (1923) The brain of the Zeuglodonlidæ (Cetacea). Proc Zool Soc Lond 93:615-654

Dechaseaux C (1961) Encephales d'artiodactyles fossiles. In: Pivetau J (ed) Traité de Paléontologie Tome 6(1). Masson et Cie, Paris, pp 1085-1104

Dechaseaux C (1969) Moulages endocrâniens d'artiodactyles primitifs, essai sur l'histoire du néopallium. Ann Paleontol $55: 195-248$

Edinger T (1955) Hearing and smell in cetacean history. Europ Neurol 129(1-3):37-58.

Fraser FC, Purves PE (1960) Anatomy and function of the cetacean ear. Proc Roy Soc 152(946):62-77

Gatesy J, Geisler JH, Chang J, Buell C, Berta A, Meredith RW, Springer MS, McGowen MR (2013) A phylogenetic blueprint for a modern whale. Mol Phylogenet Evol 66(2):479-506

Geisler JH, Luo Z (1998) Relationships of Cetacea to terrestrial ungulates and the evolution of cranial vasculature in Cete. In: Thewissen JGM (ed) The Emergence of Whales. Plenum Press, New York, pp163-212

Geisler JH, Theodor JM, Uhen MD, Foss SE (2007) Phylogenetic relationships of cetaceans to terrestrial artiodactyls. In: Prothero DR, Foss S (eds) The Evolution of Artiodactyls. The Johns Hopkins University Press, Baltimore, pp 19-31

Giannini NP, Wible JR, Simmons NB (2006) On the cranial osteology of Chiroptera. I. Pteropus (Megachiroptera: Pteropodidae). Bull Am Mus Nat Hist 295:1-134 
Gingerich PD, Arif M, Clyde WC (1995) New archaeocetes (Mammalia, Cetacea) from the middle Eocene Domanda Formation of Sulaiman Range, Punjab (Pakistan). Contrib Mus Paleontol Univ Michigan 29:291-330

Glezer II, Hof PR, Leranth C, Morgane PJ (1993) Calcium-binding protein-containing neuronal populations in mammalian visual cortex: a comparative study in whales, insectivores, bats, rodents, and primates. Cerebral Cortex 3(3):249-272

Glezer II, Jacobs MS, Morgane PJ (1988) Implications of the "initial brain" concept for brain evolution in Cetacea. Behav Brain Sci 11(1):75-89

Godfrey SJ, Geisler J, Fitzgerald EM (2013) On the olfactory anatomy in an archaic whale (Protocetidae, Cetacea) and the minke whale Balaenoptera acutorostrata (Balaenopteridae, Cetacea). Anat Rec 296(2):257-272

Hanson A, Grisham W, Sheh C, Annese J, Ridgway S (2013). Quantitative examination of the bottlenose dolphin cerebellum. Anat Rec 296(8):1215-1228

Hof PR, Chanis R, Marino L (2005) Cortical complexity in cetacean brains. Anat Rec 287(1):1142-1152

Hof PR, Van der Gucht E (2007) Structure of the cerebral cortex of the humpback whale, Megaptera novaeangliae (Cetacea, Mysticeti, Balaenopteridae). Anat Rec 290(1):1-31

Hoffmann A, Stoffel MH, Nitzsche B, Lobsien D, Seeger J, Schneider H., Boltze J (2014) The ovine cerebral venous system: comparative anatomy, visualization, and implications for translational research. PLoS One 9(4):e92990

Jerbi H, Pérez W (2018) Descriptive anatomy of artery of one-humped camel head (Camelus dromedarius). MOJ Anat Physiol 5:331-333

Karunakaran C, Ranga Rao A (1979) Status of exploration for hydrocarbons in the Himalayan region - contribution to stratigraphy and structure. Geol Surv India Misc Publ 41:1-66

Kishida T, Thewissen JGM, Hayakawa T, Imai H, Agata K (2015) Aquatic adaptation and the evolution of smell and taste in whales. Zool Lett 1(1):1-10

Knopf JP, Hof PR, Oelschläger HH (2016) The neocortex of Indian River dolphins (genus Platanista): comparative, qualitative and quantitative analysis. Brain Behav Evol 88(2):93-110

Kumar K, Sahni A (1985) Eocene mammals from the upper Subathu group, Kashmir Himalaya, India. J Vertebr Paleontol 5(2):153-168

Lebrun R, Orliac MJ (2017) MorphoMuseuM: an online platform for publication and storage of virtual specimens. Paleontol Soc Pap 22:183-195

Macrini TE (2009) Description of a digital cranial endocast of Bathygenys reevesi (Merocoidodontidae, Oreodontoidea) and implications for apomorphy based diagnosis of isolated, natural endocasts. J Vertebr Paleontol 29:1199-1211

Malmierca MS, Merchán MA, Henkel CK, Oliver DL (2002) Direct projections from cochlear nuclear complex to auditory thalamus in the rat. J Neurosci 22(24):10891-10897

Marino L (2002) Convergence of complex cognitive abilities in cetaceans and primates. Brain Behav Evol 59(1-2):21-32

Marino L (1998) A comparison of encephalization between odontocete cetaceans and anthropoid primates. Brain Behav Evol 51(4):230-238

Marino L, Connor RC, Fordyce RE, Herman LM, Hof PR, Lefebvre L, Lusseau D, McCowan B, Nimchinsky EA, Pack AA, Rendell L, Reidenberg JS, Reiss D, Uhen MD, Van der Gucht E, Whitehead H (2007) Cetaceans have complex brains for complex cognition. PLoS Biol 5(5):e139

Marino L, McShea DW, Uhen MD (2004) Origin and evolution of large brains in toothed whales. Anat Rec 281 A:1247-1255

Marino L, Uhen MD, Frohlich B, Aldag JM, Blane C, Bohaska D, Whitmore FC (2000) Endocranial volume of mid-late Eocene archaeocetes (Order: Cetacea) revealed by computed tomography: implications for cetacean brain evolution. J Mammal Evol 7(2):81-94

Marino L, Uhen MD, Pyenson ND, Fröhlich B (2003) Reconstructing cetacean brain evolution using computed tomography. Anat Rec 272B:107-117

Martínez-Cáceres M, Lambert O, Muizon C de (2017) The anatomy and phylogenetic affinities of Cynthiacetus peruvianus, a large Dorudon-like basilosaurid (Cetacea, Mammalia) from the late Eocene of Peru. Geodiversitas 39(1):7-163

Mathur NS (1978) Biostratigraphical aspects of the Subathu Formation, Kamaun Himalaya. Recent Researches in Geology 5:96-112

McFarland WL (1979) Blood supply to the brain of the dolphin Tursiops truncatus, with comparative observations on special aspects of the cerebrovascular supply of other vertebrates. Neurosci Behav Rev 3:1-93

Mead JG, Fordyce RE (2009) The therian skull: a lexicon with emphasis on the odontocetes. Smithsonian Contrib Zool 627:1-248

Medlicott HB (1876) Notes on the Sub-Himalyan series in the Jammu (Jammoo) Hills. Rec Geol Surv India 9:49-57

Melnikov VV (1997) The arterial system of the sperm whale (Physeter macrocephalus). J Morphol 234(1):37-50

Mourlam MJ, Orliac MJ (2017) Infrasonic and ultrasonic hearing evolved after the emergence of modern whales. Curr Biol 27(12):1776-1781.e9

Mourlam MJ, Orliac MJ (2019) Early evolution of the ossicular chain in cetacea: into the middle ear gears of a semi-aquatic protocetid whale. Proc R Soc B 286(1912):20191417

Morgane PJ, Glezer II, Jacobs MS (1988) Visual cortex of the dolphin: an image analysis study. J Comp Neurol 273(1):3-25 
Morgane PJ, Jacobs MS, Galaburda A (1985) Conservative features of neocortical evolution in dolphin brain. Brain Behav Evol 23:176-184

Nummela AS, Hussain ST, Thewissen JGM (2006) Cranial anatomy of Pakicetidae (Cetacea, Mammalia). J Vertebr Paleontol 26:746-759

Nummela S, Thewissen JGM, Bajpai S, Hussain ST, Kumar K (2004) Eocene evolution of whale hearing. Nature 430(7001):776-778

O’Brien HD (2015) Cranial arterial pattern of the Sri Lankan spotted chevrotain, Moschiola memmina, and comparative basicranial osteology of the Tragulidae. PeerJ 3:e1451

Ogawa T, Arifuku S (1948) On the acoustic system in the cetacean brains. Sci Rep Whales Res Inst Tokyo 2:1-20

Orliac MJ, Antoine PO, Charruault AL, Hervet S, Prodeo F, Duranthon F (2013) Specialization for amphibiosis in Brachyodus onoideus (Artiodactyla, Hippopotamoidea) from the early Miocene of France. Swiss J Geosci 106(2):265-278

Orliac MJ, Ducrocq S (2012) Eocene raoellids (Mammalia, Cetartiodactyla) outside the Indian Subcontinent: palaeogeographical implications. Geol Mag 149(1):80-92

Orliac MJ, Gilissen E (2012) Virtual endocranial cast of earliest Eocene Diacodexis (Artiodactyla, Mammalia) and morphological diversity of early artiodactyl brains. Proc Roy Soc B 279(1743):3670-3677

Orliac M, Guy F, Lebrun R (2014) Osteological connections of the petrosal bone of the extant Hippopotamidae Hippopotamus amphibius and Choeropsis liberiensis. MorphoMuseum J 1(1)-e1:1-6

Peri E, Gingerich PD, Aringhieri G, Bianucci G (2020) Reduction of olfactory and respiratory turbinates in the transition of whales from land to sea: the semiaquatic middle Eocene Aegyptocetus tarfa. J Anat 236:98-104

Pihlstrom H (2008) Comparative anatomy and physiology of chemical senses in aquatic mammals. In: Thewissen JGM, Nummela S (eds) Sensory Evolution on the Threshold, Adaptations in Secondarily Aquatic Vertebrates. University of California Press, Berkeley, pp 95-112

Pilleri G (1966a) Morphology of the brain of the humpback whale, Megaptera novaeangliae Borowski (Cetacea, Mysticeti, Balaenopteridae). J Hirnforsch 8(5):437-491

Pilleri G (1966b) Über die Anatomie des Gehirns des Ganges Delphins, Platanista gangetica. Rev Suisse Zool 73 :113-118

Pilleri G (1991) Betrachtungen über das Gehirn der Archaeoceti (Mammalia, Cetacea) aus dem Fayum Agyptens. Investigations on Cetacea 23:193-211

Raghanti MA, Wicinski B, Meierovich R, Warda T, Dickstein DL, Reidenberg JS, Tang CY, George JC, Thewissen JGM, Butti C, Hof PR (2019). A comparison of the cortical structure of the bowhead whale (Balaena mysticetus), a basal mysticete, with other cetaceans. Anat Rec 302(5):745-760

Ranga Rao A (1971) New mammals from Murree (Kalakot Zone) of the Himalayan foot hills near Kalakot, Jammu and Kashmir state, India. J Geol Soc India 12:125-134

Ranga Rao A (1972) New mammalian genera and species from the Kalakot zone of Himalayan foot hills near Kalakot, Jammu and Kashmir State, India. Special Paper of the Directorate of Geology, Oil, and Natural Gas Commission, Dehra Dun, India 1:1-22

Ries FA, Langworthy OR (1937). A study of the surface structure of the brain of the whale (Balaenoptera physalus and Physeter catodon). J Comp Neurol 68(1):1-47

Ridgway SH, Tarple VRJ (1996) Brain mass comparisons in Cetacea. Proc Internatl Assoc Aquat Anim Med 27:55-57

Russell DE, Zhai R (1987) The Paleogene of Asia: mammals and stratigraphy. Mém Mus Natl Hist Nat 52:1-488

Sahni A, Khare SK (1971) Three new Eocene mammals from Rajouri District, Jammu and Kashmir. J Palaeontol Soc India $14: 41-53$

Sahni A, Khare SK (1973) Additional Eocene mammals from the Subathu Formation of Jammu and Kashmir. J Palaeontol Soc India 17:31-49

Serio C, Castiglione S, Tesone G, Piccolo M, Melchionna M, Mondanaro A, Di Febbraro M, Raia P (2019). Macroevolution of toothed whales exceptional relative brain size. Evol Biol 46(4):332-342

Simpson RR (1904) Report on the Jammu coalfields. Mem Geol Surv India 32:189-225

Singh BP, Andotra DS (2000) Barrier lagoon and tidal cycles in Paleocene to middle Eocene Subathu Formation, NW Himalaya, India. Tertiary Research 20:65-78

Slijper EJ (1936) Die Cetaceen. Vergleichend-anatomisch und systematisch. Capita Zoologica 7-8:1-590

Smith GE (1903) The brain of the Archaeoceti. Proc Roy Soc 71:322-331

Thewissen JGM (2014) The Walking Whales: from Land to Water in Eight Million Years. University of California Press, Berkeley, 245pp

Thewissen JGM, Bajpai S (2009) New skeletal material of Andrewsiphius and Kutchicetus, two Eocene cetaceans from India. J Paleontol 83(5):635-663

Thewissen JGM, Cooper LN, Clementz MT, Bajpai S, Tiwari BN (2007) Whales originated from aquatic artiodactyls in the Eocene epoch of India. Nature 450(7173):1190-1194 
Thewissen JGM, Cooper LN, George JC, Bajpai S (2009) From land to water: the origin of whales, dolphins, and porpoises. Evolution: Education and Outreach 2:272-288

Thewissen JGM, Madar SI, Hussain ST (1996) Ambulocetus natans an Eocene cetacean (Mammalia) from Pakistan. Cour Forsch-Inst Senckenberg 191:1-86

Thewissen JGM, Nanda AC, Bajpai S (2020) Indohyus, endemic radiation of raoellid artiodactyls in the Eocene of India and Pakistan. In: Prasad GVR, Patnaik R (eds) Biological Consequences of Plate Tectonics New Perspectives on PostGondwana: Break-up-A Tribute to Ashok Sahni. Springer, Cham, pp 337-346

Thewissen JGM, Williams EM, Hussain SM (2001) Eocene mammal faunas from northern Indo-Pakistan. J Vertebr Paleontol 21:347-366

Uhen MD (2004) Form, function, and anatomy of Dorudon atrox (Mammalia, Cetacea): an archaeocete from the middle to late Eocene of Egypt. Pap Paleontol 34:1-222

Vogl AW, Fisher HD (1981) Arterial circulation of the spinal cord and brain in the Monodontidae (Order Cetacea). J Morphol 170(2):171-180

Wible JR (1990) Petrosals of Late Cretaceous marsupials from North America and a cladistic analysis of the petrosal in therian mammals. J Vertebr Paleontol 10(2):183-205

Wible JR (1993) Cranial circulation and relationships of the colugo Cynocephalus (Dermoptera, Mammalia). Am Mus Novitates 3072:1-27

Wible JR (2008) On the cranial osteology of the hispaniolan solenodon, solenodon paradoxus brandt, 1833 (Mammalia, lipotyphla, solenodontidae). Ann Carnegie Mus 77(3):321-402

Wible JR (2011) On the treeshrew skull (Mammalia, Placentalia, Scandentia). Ann Carnegie Mus 79(3):149-230

Whitmore FC (1953) Cranial morphology of some Oligocene Artiodactyla. Geol Surv Prof Pap 243:117-160

Worthy GA, Hickie JP (1986) Relative brain size in marine mammals. Am Nat 128(4):445-459

\section{EXPLANATION OF FIGURES AND PLATES}

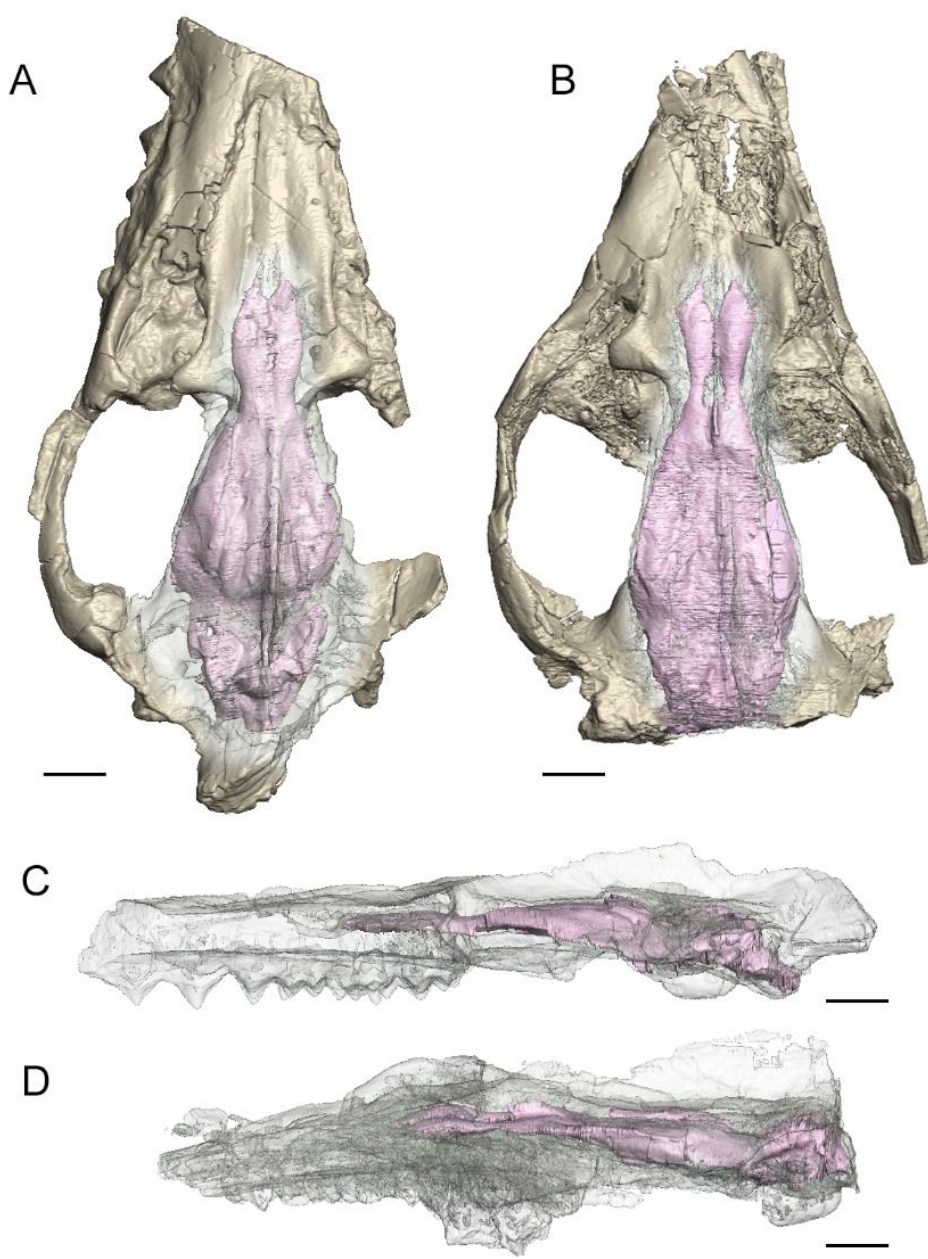


Fig. 1. Crania of Indohyus indirae showing the endocranial cast. a, c, RR 207; b, d, RR 601; $\mathbf{a - b}$, dorsal views; $\mathbf{c}-\mathbf{d}$, left lateral views. Scale bars $=1 \mathrm{~cm}$.
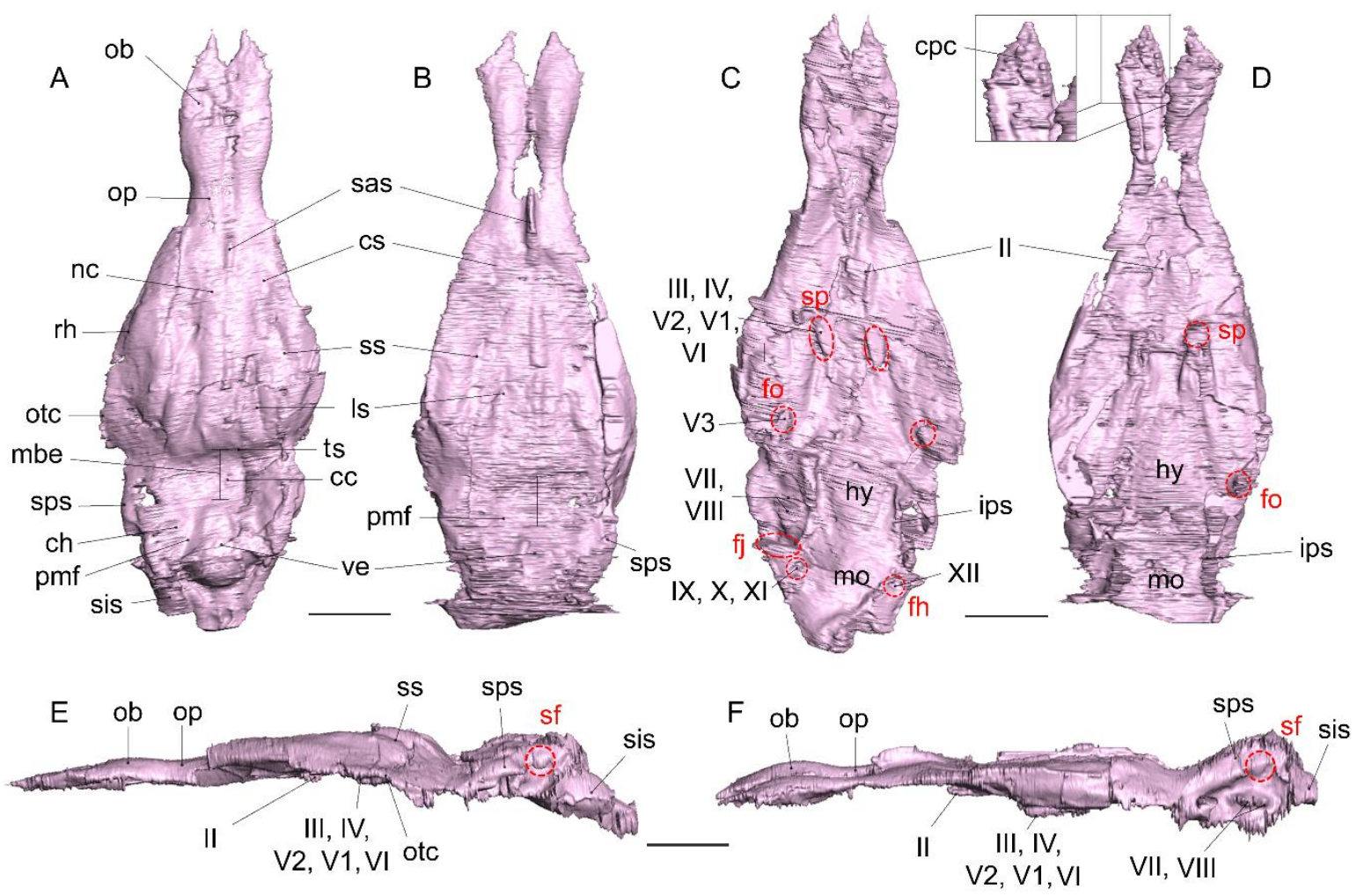

Fig. 2. Labelled endocasts of Indohyus indirae. a, c, e, RR 207; b, d, f, RR 601 illustrated in a-b, dorsal, c-d, ventral, e-f left lateral views. Scale bars $=1 \mathrm{~cm}$. Abbreviations: ch, cerebral hemisphere; cpc, cribriform plate cast; cs, coronal sulcus; fj, foramen jugulare; fh, foramen hypoglossi; fo, foramen ovale; hy, hypophysis; cc, caudal colluculus; ; ips, inferior petrosal sinus; ls, lateral sulcus; mbe, midbrain exposure; mo, medulla oblongata; nc, neocortex; ob, olfactory bulb; op, olfactory peduncle; otc, orbitotemporal canal; pmf, paramedian fissure ; rh, rhinal fissure; sas, dorsal sagittal sinus; sf, subarcuate fossa; sis, sigmoid sinus; sp, sphenorbital fissure; sps, superior petrosal sinus; ss, suprasylvia; ve, vermis. Impressions of foramina are indicated in red dashed lines. II to XII refer to cranial nerves. 

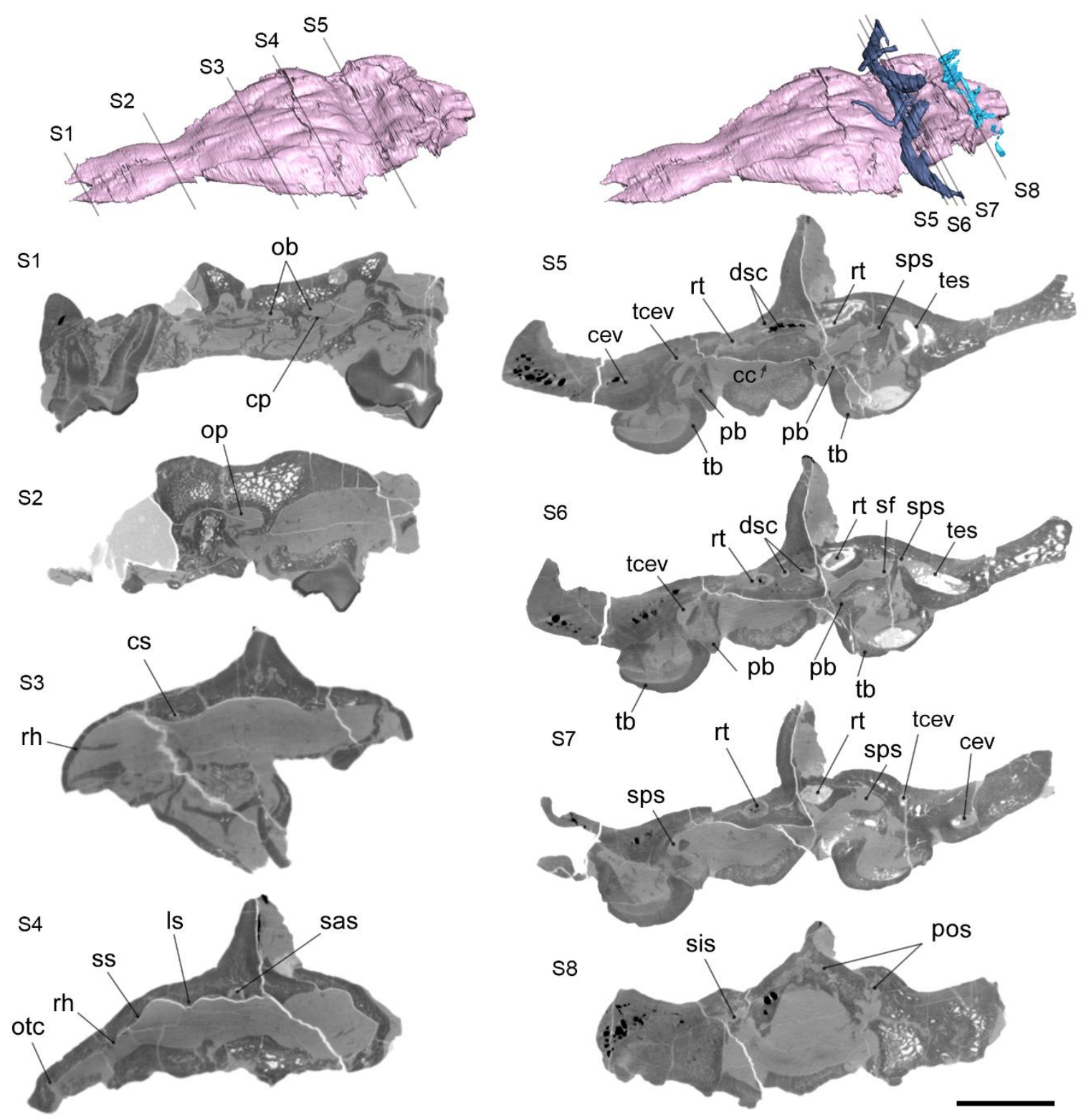

Fig. 3. Labelled CT slices through the cranium of Indohyus indirae (specimen RR 207). Arrows indicate the location of caudal colliculi. Abbreviations: cev, canal for capsuloparietal emissary vein; cp, cribriform plate; cs, bone swelling marking the coronal sulcus; dsc, dorsal confluence of sinuses; cc, caudal colliculus; ls, lateral sulcus; ob, olfactory bulb; op, olfactory peduncle; otc, orbitotemporal canal; pb, petrosal bone; pos posterior occipital sinus; rh, bone swelling marking the rhinal fissure; rt, canal for ramus temporal; sas, sagittal sinus; sis, sigmoid sinus; sps, superior petrosal sinus; ss, bone swelling marking the suprasylvia; tb, tympanic bulla; tcpev, canal for tributary branch of capsuloparietal emissary vein; tes, temporal sinus. Scale bars $=1 \mathrm{~cm}$. 

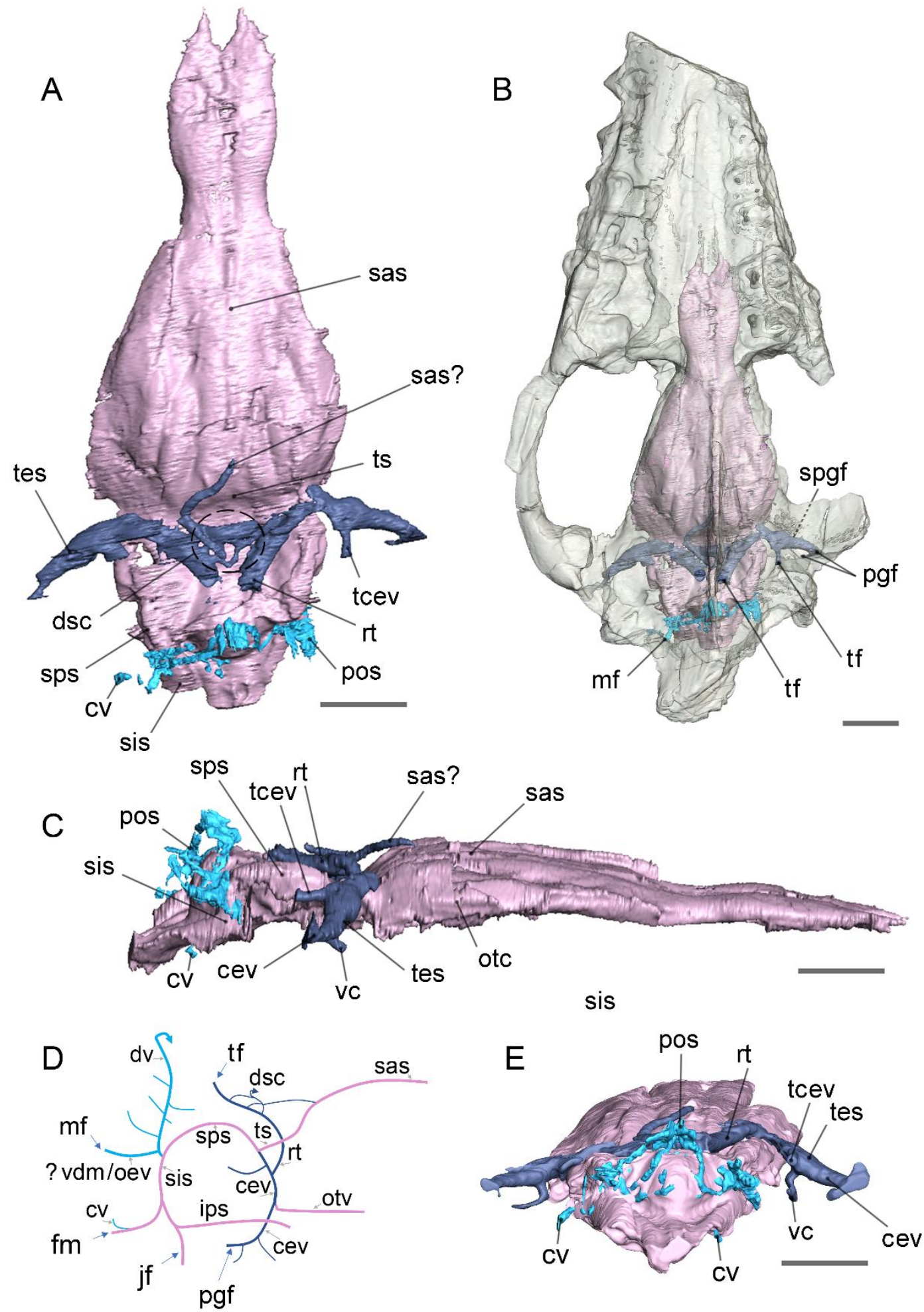

Fig. 4. Labelled 3D model of the endocranial cast and associated sinuses of Indohyus indirae (specimen RR 207) in a-b dorsal, c lateral, e posterior views; d, reconstruction of a plausible venous pattern in the posterior portion of the cranium in lateral view, right side; pink, cast of the main cavity of the braincase; light blue, intraosseous sinuses; dark blue, intraosseous sinuses related to the temporal sinus; light blue intraosseous sinuses within occipital. Abbreviations: cev, canal for capsuloparietal emissary vein; cp, cribriform plate;cs, bone swelling marking the coronal sulcus; cv, condyloid vein; dsc, dorsal confluence of sinuses 
indicated by the dashed circle; $\mathrm{dv}$ diploic veins; fm, foramen magnum; ls, lateral sulcus; $\mathrm{mf}$, mastoid foramen; ob, olfactory bulb; oev, occipital emissary vein; op, olfactory peduncle; otc, orbitotemporal canal; otv orbitotemporal vein; pb, petrosal bone; pos posterior occipital sinus; $\mathrm{rh}$, bone swelling marking the rhinal fissure; rt, canal for ramus temporalis; sas, sagittal sinus; sis, sigmoid sinus; spgf, secondary postglenoid foramen; sps, superior petrosal sinus; ss, bone swelling marking the suprasylvia; tb, tympanic bulla; tcev, canal for tributary branch of capsuloparietal emissary vein; tes, temporal sinus; vc, vascular canal; vdm vein diploetica magna. For additional views illustrating the spgf, see Fig. S3. Scale bars $=1 \mathrm{~cm}$.

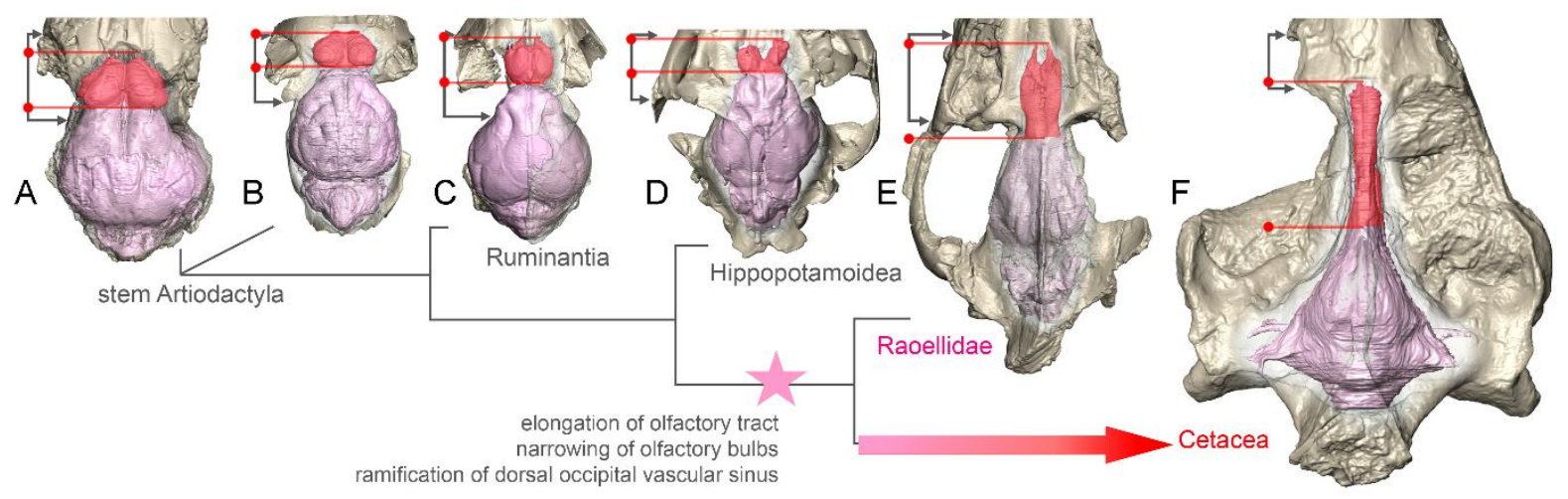

Fig. 5. Position and shape of the braincase in Paleogene artiodactyls: a, Diacodexis ilicis (Diacodexeidae, AMNH VP 16141); b, Dichobune leporina (Dichobunoidea; MNHN Qu16586); c, Leptomeryx sp. (Ruminantia; AMNH SD103-1975); d, Microbunodon minimum (Hippopotamoidea; LM1967MA300); e, Indohyus indirae (Raoellidae; RR 207); f, Remingtonocetus harudiensis (Cetacea; IITR-SB 2770). Olfactory bulbs and peduncles are highlighted in red. Extent of the orbit is indicated by the grey arrows. Not to scale, specimens are all represented with the same cerebral length in order to illustrate the relative proportion of brain components.

\begin{tabular}{|l|l|l|}
\hline & RR 207 & RR 601 \\
\hline Endocast maximum length & 74.2 & 73.1 \\
\hline Olfactory bulb cast anteroposterior length & 18.0 & 15.6 \\
\hline Olfactory bulb cast maximal width & 11.7 & 11.6 \\
\hline Olfactory tract length anterior to cerebrum & 24.9 & 23.3 \\
\hline Cerebrum cast anteroposterior length & 32.4 & 28.8 \\
\hline Cerebrum cast maximal width & - & $27.4^{*}$ \\
\hline Midbrain maximal exposure & 3.6 & 4.0 \\
\hline Cerebellum cast anteroposterior length & $11.6^{*}$ & $12.4^{*}$ \\
\hline Cerebellum cast maximal width & - & - \\
\hline
\end{tabular}

Table 1. Endocranial cast measurements for Indohyus indirae (in mm); asterisks indicate measurement potentially slightly affected by deformations. 